\section{P 013 COMPREHENDING THE INEXPLICABLE: QUALITATIVE ACCOUNTS OF BLACK CARIBBEAN AND WHITE BRITISH PEOPLE SEVERELY AFFECTED BY MULTIPLE SCLEROSIS}

Jonathan Koffman, ${ }^{1}$ Cassie Goddard, ${ }^{1}$ Eli Silber, ${ }^{2}$ Rachel Burman, ${ }^{1}$ Pauline Shaw ${ }^{2}$ Fiona Barnes, ${ }^{2}$ Peter Speck, ${ }^{1}$ Irene Higginson ${ }^{1} .{ }^{1}$ King's College London, London, United Kingdom; ${ }^{2}$ Kings College Hospital Nhs Foundation Trust

\subsection{6/bmjspcare-2014-000654.54}

Background Multiple sclerosis is now more common among minority ethnic groups in the UK but little known little is known about how they attribute meanings to their illness and to what extent they are culturally shaped; meanings may influence adjustment outcomes and attitudes to service use.

Aim To explore the cognitive organisation and meanings of MS among black Caribbean (BC) and white British (WB) people severely affected by their illness and to understand how these may be culturally constructed.

Method Semi-structured qualitative interviews were conducted among Black Caribbean (BC) and White British (WB) people with MS (PwMS) with an EDSS of $\geq 6.0$ (severe disease). Data were analysed using the framework approach.

Results 15 BC and 15 WB PwMS were interviewed with mean ages of 46.6 and 56.9 years respectively. Attributions were complex, with most PwMS reporting multiple explanations. Uncertainty, represents the first theme surrounding the aetiology of MS where participants constantly rehearsed "why me?" question in relation to their illness, a number citing considerable frustration. The second main theme, 'logical and scientific', was voiced more often by WB PwMS and accounts for arrange of genetic/viral influences, stress, environmental and lifestyle factors. Third, the 'supernatural' illness attribution theme departs from a biomedical perspective and was reported more frequently among BC PwMS. This theme included the subcategories of religious challenge and divine punishment, a view although exclusive to BC participants was sometimes in conflict with their notions of modernity.

Conclusion We identify causal attributions play important roles in determining emotional responses to MS. Taken together these findings suggest not only considerable cultural diversity in relation to MS causation but also diversity within groups. This highlights the need for health professionals to investigate such beliefs, particularly if supernatural causes are considered inherently uncontrollable. This has important implications for helpseeking and symptom-reporting behaviours. 